\title{
Assessment of the Impact of Income Inequality on Population's Migration
}

\author{
Daiva Laskiene ${ }^{1}$, Ineta Zykiene ${ }^{2}$, Paulina Verdnikovaite ${ }^{3}$
}

\author{
Kaunas University of Technology \\ K. Donelaicio st. 73, LT-44029, Kaunas, Lithuania \\ E-mail.daiva.laskiene@ktu.lt; ineta.zykiene@ktu.lt; paulina.verdnikovaite@gmail.com \\ cross $^{\text {ref }}$ http://dx.doi.org/10.5755/j01.ee.31.5.25193
}

Income inequality and population's migration are economic processes ongoing in every country, but their scales are different. Although both phenomena - income inequality and population's migration - earn sufficient scientific attention, scientific literature is still lacking comprehensive studies on interdependence between them. This research is aimed at the assessment of the impact of income inequality on population's migration. This article highlights how significant it is to assess the impact of income inequality on population's migration, and reviews the issues of income inequality and population's migration previously analysed in scientific studies. The research is based on the methodology developed for the EU Member States. The paper provides original perspective as the EU Member States are divided into six groups by their income inequality and net migration rates and the impact of income inequality on population's migration is researched in particular groups of the current EU Member States by applying the methods of correlation and regression analysis. The results of the research indicate that the impact of income inequality on population's migration differs within and between the EU Member State groups. Research results revealed that, income inequality has a more significant impact on population's immigration than on emigration in all EU Member State groups. Income inequality causes population's emigration only in the states with medium income inequality rates. The paper contributes to the scientific literature of regional development as the quantitative analysis of the interconnection between income inequality and population's migration is scarce.

Keywords: Income Inequality; Population's Migration; Net Migration Rate; Gini Coefficient; EU Member States.

\section{Introduction}

Income plays an extremely important role in every person's life, but the structure of market economy determines unequal income growth rates, which, in turn, lead to population's exclusion and significant gaps in their quality of life. Therefore, the aim of every state is to create and ensure welfare for its citizens. However, when particular population groups in the same state live much better than others, society disunites, and a large proportion of citizens start expressing their dissatisfaction with the current situation. High income inequality rates cause not only social, but also economic problems, which, in turn, impede national economic development and welfare growth. Strive for better life is the biggest incentive for migration. Being unable to satisfy their needs, expand consumption and self-actualize, people make a decision to change their place of residence, which suggests that income inequality and population's migration are interrelated. Emigration is a threat to a country's economic growth, cultural identity and demographic development. Martinaitis and Zvalionyte (2007) treat emigration as the most dangerous non-military threat to a state. Immigration also causes particular problems: host countries face such challenges as a growing number of population, ecologic, assimilation issues, etc.

Numerous scientific works analyse the main factors of immigration and income inequality and also provide suggestions for policy implications. Scientists analyse the impact of income inequality to economic development but the results vary because of used different indicators of income inequality and factors of economic development (Brzezinski, 2013; Halter, Oechslin, \& Zweimuller, 2014, Guvenen, Kuruscu \& Ozkan, 2014). As income inequality and emigration are interdependent variables the paper provides original perspective as it is based on theories, which analyse the reasons of migration and combines analysis of neoclassical economic theory (Krugman \& Obstfeld, 2003; Tsoukalis, 1993; Jovanovich, 2002) and theory which explains the emigration on the basis of income inequality (Porumbescu, 2015; Massey, VilaBelda, Hugo, Kouaouci, \& Pellegrino, 2006). Authors discuss if income inequality is one of the main causes of emigration, which reflects neoclassical economic theory (Krugman \& Obstfeld, 2003; Tsoukalis, 1993; Jovanovich, 2002), and how the emigration affects income inequality in the source country, which comes in line with the theory of emigration on the basis of income inequality (Porumbescu, 2015; Massey, Vila-Belda, Hugo, Kouaouci, \& Pellegrino, 2006).

Statistics and studies show that income inequality as well as intensive flows of migrants within the EU are the most topical issues causing a number of negative outcomes. Income inequality emerges due to unequal household income growth, high unemployment rates, inefficient state budget redistribution, the differences in labour force education and qualification, property gaps and passiveness of labour unions (Lazutka, 2017; Lynch, 2017). The growth in income differentiation reduces GDP and investment rates, and leads to regional disparities. 
Moreover, many scientists (Stark, 2005; Card, 2009; Dauderstadt, 2017; Burzynski et al., 2019; Collins, 2020; Ganic, 2019; Mishchuk et al., 2018; Slettebak, 2020) agree that income inequality is one of the main causes of emigration. Due to the reasons explicated above, it is extremely important to assess what impact income inequality has on population's migration since combination of these problems has negative effects on both the entire state and each individual. In addition, if income inequality can cause population's migration, population's migration can affect income inequality (Porumbescu, 2015). Koczan \& Loyola (2018), Orrenius \& Zavodny (2018), Uprety (2019) examine if emigration causes income inequality, which shows that interconnection between emigration and income inequality might be a complex issue. The latter can start decreasing due to the emigration of indigent people or start increasing due to the growth in the number immigrants who usually earn lower wages than the local population, to say nothing of higher concentrations of assets in local households.

Income inequality and population's migration are the problems which exist in any country, but the scales of these problems in some countries are smaller than in others. Therefore, to assess the real scale of the problem, it is necessary to consider not only national situation, but also the context of the EU as a whole.

Although scientific literature is rich in the studies on the issues of income inequality and population's migration, the interdependence between these two phenomena still calls for a deeper insight and assessment.

This research is aimed at the assessment of the impact of income inequality rates on population's migration rates in the EU. The impact of income inequality on population's migration is researched for particular groups of the current EU Member States by applying the methods of correlation and regression analysis.

\section{Literature Review}

Scientific literature analyses the different aspects of the interdependence between income inequality and population's migration.

According to Skuciene (2008), household differences condition the emergence of other negative phenomena. The author notes that although the relationship between income inequality and population's migration has not still been comprehensively researched, the results of previous studies propose that with reference to the theory of relative deprivation (i.e. the mismatch between what people get and what they think they have the right to), people with lowest income are most inclined to leave their countries of origin in search of better-paid jobs. Stark's (2005), Porumbescu (2015) and Ganic (2019) studies revealed that there exists the relationship between income inequality, measured by Gini index, and population's migration. Privation is the strongest motive for population's migration. When other conditions remain unchanged, higher income inequality pushes more people to emigrate. The decision to emigrate is determined by the differences in income inequality rates in the countries of origin and destination (Krugman \& Obstfeld, 2003; Jovanovich, 2002).
Kumpikaite and Zickute (2012), Ganic (2019) agree that population's migration is caused by economic factors. The authors attribute wage and income disparities to the group of the main factors causing most intensive emigration flows. Minimal monthly wages have the most significant impact on the conditions of normal functioning of the employed. Thus, an increase in minimal or average monthly wages can serve as a measure to promote return migration or motivate people to refrain from emigration because the decision to emigrate is determined not only by the current situation in a country, but also by assessment of future prospects. Promotion of the expectations that the national economy will develop, average wages will grow and wage differentiation will decrease, may help more effectively manage soaring migration flows and prompt emigrants to return to their homeland.

According to Barciukiene (2007), poverty causes intensive emigration flows. Job is the main factor providing the feelings of stability and safety, ensuring income and helping to satisfy the basic needs of population, while unemployment is one of the main causes of poverty. Running away from poverty, searching for a better life and a more stable, better-paid job, people change their place of residence. Emigration from a country reduces its poverty and unemployment rates since the poor and unemployed people make the largest flows of emigrants. Skuciene and Gabnyte (2018) add that emigration is one of the outcomes of regional economic disparities and social exclusion. Higher poverty rates are inherent to rural areas. Insufficient satisfaction of personal needs causes migration of the rural population. Rural areas lack investment, work places, infrastructures, learning opportunities, service supply, etc. Namely for this reason, emigration from rural areas is a common phenomenon, especially among young people. High youth emigration rates negatively affect demographic indicators of an area. It is important to note that the unemployed or the poor are not the specific population groups that emigrate. Skilled labour force, scientists, professionals can also make the decision to emigrate if they feel that their efforts and skills are underestimated, wages are uncompetitive, work conditions are poor and carrier opportunities are vague (Dodani \& LaPorte, 2005; Uprety, 2019). This is the problem of brain drain. Skilled professionals transfer their knowledge and skills to a host country and thus contribute to its welfare. Although host countries are still facing the problems of inefficient resource redistribution, the additional immigrant labour force much contributes to their value added and economic development (Pukeliene, Glinskiene \& Berzinskiene, 2007). The economies with declining labour force are growing much slower, which leads to the disparities in the income earned by the local population and the population working abroad. On the other hand, as it was noted by Schiff (2018), brain drain can even be beneficial to a country of origin as it can help to solve the problem of income inequality. First of all, since a substantial share of emigrants is composed of high-paid professionals, the average wages in the country of origin decline. Financial remittances transferred by emigrants to their family members also reduce income disparities (Howell, 2017; Kusunose, \& Rignall, 2018), promote 
investment, communications, international business cooperation and sharing the valuable experience.

Another topical issue is brain waste. According to Giziene and Markauskiene (2012), brain waste is referred to as a type of emigration when skilled professionals, driven by economic reasons, choose better-paid, but lowerskilled jobs abroad. In this case, human potential as well as investments in human capital are wasted.

Tonkunaite-Thiemann (2012) treats free movement of people as a fundamental right of EU citizens who are free and independent to flee poverty, look for better employment opportunities or better-paid jobs abroad. Mobility is interpreted as an alternative allowing to raise personal welfare and escape the trap of social inequality in a home country. At the same time, emigration is treated as a threat to the total number of population and labour force in a home country since it causes the problems of slower economic and social development, demographic changes and aging society. Lower budget revenues from taxes complicate the effective fight against income inequality, i.e. they do not allow to increase the income for most vulnerable social groups. As a result, inefficient governmental fight against income inequality promotes people's emigration from the country that cannot ensure basic standards of living and appropriate protection from social risks (e.g., loss of income when a person falls ill, becomes unemployed, loses main residence, etc.). On the other hand, taking advantage of foreign welfare systems may push people to abuse social guarantees, promotes nonparticipation in the labour market and reliance on state support.

Migration is driven not only by inadequate living conditions in a home country. A promising host country's welfare system, opportunities to establish oneself in the labour market and various social programs may attract the people who have not previously considered such opportunity (Collins, 2020; Ganic, 2019; Slettebak, 2020). Nevertheless, as it was noted by Tonkunaite-Thiemann (2012), even an attractive host country's environment does not ensure better income or higher quality of life. Previous studies show that migration can be driven not only by income inequality; an inverse relationship between these two phenomena is also possible. The status of an immigrant is one of the main determinants of social exclusion and poverty risk. Immigrants often face discrimination in the labour and housing markets; the issuance of residence permits is also restricted. Moreover, social exclusion of immigrants may even be deepened by insufficient internal resources - poor skills of foreign languages, lack or repudiation of education, inadequate qualification for the foreign labour market, personal characteristics, etc.

Barham and Boucher (1998) as well as Arslan and Taylor (2012) state that emigrants' financial remittances can reduce income inequality, which is extremely important to developing countries where overall household income is low, household income disparities are extreme, and financial remittance flows serve as an additional source of income. The more funds emigrants transfer to the needy relatives in their country of origin, the smaller are income distribution and consumption disparities (Howell, 2017; Kusunose \& Rignall, 2018). Matuzeviciute and
Balciunas (2012) note that the largest share of financial remittances are used for daily consumption, but this share is smaller than the share of Lithuanian household income used for the same purpose.

Although the links between income inequality and population's migration have not still been comprehensively researched, the results of previous studies propose that the higher is income inequality, the greater are emigration rates. The key incentives for emigration are low wages that impede fulfilment of the basic needs. Extremely high levels of poverty are inherent to rural areas. Income inequality pushes to emigration not only low-skilled, but also high-skilled labour force which deepens the income inequality in source country (Uprety, 2019). This way, the potential of the latter is not exploited in their native county, but transferred abroad. Emigration of the people with comparatively high income statistically reduces inequality, while financial remittances transferred to low-income family members in the country of origin help to actually reduce household poverty (Howell, 2017; Kusunose \& Rignall, 2018). Nevertheless, although income inequality in an emigrant's country of origin can shrink, it can rise in a host country since immigrants may find it difficult to find a better-paid job and earn stable income. Hence, the relationship between income inequality and population's migration is multifaceted and requires further research.

Analysis of scientific literature revealed that most researches for evaluation of link between income inequality and migration use various factors which influence them. For this purpose authors apply qualitative and quantitative methods. With this paper our focus is to analyse not the factors but the scale of income inequality and migration. Authors aim is to evaluate if scale of migration depends on the level of income inequality in certain countries. The analysis is carried out for countries of European Union which differ both in income inequality and migration levels even though they belong to one region and have not only differences but also similarities in their policy patterns. This perspective makes presented research original and novel.

\section{The Methodology of the Research Concerning the Impact of Income Inequality on Population's Migration}

As income inequality rates may vary, it is important to research how income inequality affects migration rates in different EU country groups. Grouping method is employed for identification of object similarities; it also allows to group the objects so that the differences within the groups would be as small as possible, but the differences between the groups would be as great as possible (Pukenas, 2005). The main purpose of grouping in this research is to reveal the impact of income inequality on population's migration in the countries with different income inequality rates and different migration flows. Under the conditions of free movement of people, different country groups may have different impacts of income inequality on population's migration. Moreover, the trends of these two phenomena may also differ, which may as well determine different impacts of income inequality on population's migration. By employing correlation and 
Daiva Laskiene, Ineta Zykiene, Paulina Verdnikovaite. Assessment of the Impact of Income Inequality on ...

regression analyses, we identify and assess the relationship between income inequality and population's emigration and immigration in particular EU country groups.

In statistics, the correlation coefficient measures linear interdependence between two interval variables. The first step of the correlation analysis is to estimate $\mathrm{p}-$ the value of marginal significance. The resulting $p$-value is compared to the selected cutoff for significance 0.05 . If the relationship is statistically insignificant $(p>0.05)$, it means that the changes in one variable do not have any impact on the other. The correlation coefficient may vary in the interval from -1 to 1 . A positive value of the correlation coefficient indicates a direct relationship: the values of the factor and result attribute vary in the same direction - an increase in one of them causes an increase in the other, and vice versa. A negative value of the correlation coefficient indicates an inverse relationship: the values of the factor and result attribute vary in different directions - an increase in one of them causes a decrease in the other, and vice versa. The values of the correlation coefficient are described in Table 1.

Regression analysis reveals the nature of a statistical relationship, describes the dependence of the mean ranks of a dependent (effect) variable on the values of one or several independent (cause) variables by the mathematical formula, and at the same time forecasts the values of the former variable (Kasiulevicius and Denapiene, 2008).

According to Bekesiene (2015), regression analysis shows how the values of a dependent variable are going to change with the changes in an independent variable. The accuracy of a regression model is described by the coefficient of determination. It indicates which part of the overall variation in one attribute can be explained by the variation in another attribute.

Table 1

Assessment of the Correlation Coefficient (Compiled with Reference to Kasiulevicius and Denapiene, 2008)

\begin{tabular}{|l|l|l|}
\hline Positive relationship & Relationship strength & Negative relationship \\
\hline 0 & No relationship & 0 \\
\hline From 0.01 to 0.19 & Very weak & From -0.01 to -0.19 \\
\hline From 0.2 to 0.39 & Weak & From -0.2 to -0.39 \\
\hline From 0.4 to 0.69 & Medium & From -0.4 to -0.69 \\
\hline From 0.7 to 0.89 & Strong & From -0.7 to -0.89 \\
\hline From 0.9 to 1 & Very strong & From -0.9 to -1 \\
\hline
\end{tabular}

Bekesiene (2015) notes that the higher is the coefficient of determination (with its maximal value equal to 1 ), the more accurate forecast of a dependent variable from an independent one can be obtained. The model of linear regression is developed by the formula (Bekesiene, 2015):

$$
\mathrm{Y}=\alpha+\beta \mathrm{X}+\varepsilon
$$

here: $\mathrm{Y}-$ a dependent variable

$$
\begin{aligned}
& \alpha-\text { a regression model coefficient } \\
& \beta-\text { a regression model coefficient } \\
& X-\text { an independent variable } \\
& \varepsilon-\text { random error }
\end{aligned}
$$

The research covers the data for the EU Member States over the period 2007 to 2017. A ten-year period is sufficient to reveal variation in the indicators. The EU Member States were selected for the research because of their similarities and differences. In addition, the data for the twenty-eight current EU Member States are available in Eurostat database.

The research is processed in the following stages:

- Net migration rate per 1000 persons over the period 2007 to 2017 is estimated for each EU Member State. Net migration rate per 1000 persons was selected as an additional indicator to net migration since such estimation allows to equalize and compare the states with different population and migration rates. Net migration rate per 1000 persons is the difference between the number of persons having entered the territory and the number of persons having left the territory estimated for 1000 people (Kaminskiene, 2009). A positive net migration rate per 1000 persons indicates that a country has more immigrants than emigrants, while a negative net migration rate per 1000 persons shows that a country has more emigrants than immigrants. By the value of this indicator, the states under consideration are divided into two groups: the states with a positive net migration rate and the states with a negative net migration rate for 1000 persons.

- The states under consideration are divided into three groups by their income inequality rate over the period 2007 to 2017 . Income inequality rate is reflected by Gini index. The states under consideration are grouped by the values of Gini index, presented in Table 2:

○ the states with a low income inequality rate (Gini index is lower than 25);

$\circ$ the states with a medium income inequality rate (Gini index varies between 25 and 35);

○ the states with a high income inequality rate (Gini index is higher than 35).

By the similarities in their net migration rate per 1000 persons and income inequality attributes, all the

\begin{tabular}{|c|c|c|c|c|c|}
\hline \multicolumn{2}{|l|}{ Group I } & \multicolumn{2}{|l|}{ Group II } & \multicolumn{2}{|l|}{ Group III } \\
\hline Net migration rate & Gini index & Net migration rate & Gini index & Net migration rate & Gini index \\
\hline Positive & $<0.25$ & Positive & $0.25<$ Gini index $<0.35$ & Positive & $>0.35$ \\
\hline \multicolumn{2}{|l|}{ Group IV } & \multicolumn{2}{|l|}{ Group V } & \multicolumn{2}{|l|}{ Group VI } \\
\hline Net migration rate & Gini index & Net migration rate & Gini index & Net migration rate & Gini index \\
\hline Negative & $<0.25$ & Negative & $0.25<$ Gini index $<0.35$ & Negative & $>0.35$ \\
\hline
\end{tabular}
states under consideration are divided into 6 groups, presented in Table 2.

Table 2

State Groups by their net Migration Rates per 1000 Persons and Gini Index 
- The correlation between Gini index and net migration rate in each of the states over the period 2007 to 2017 is researched. Assessment of the correlation helps to ascertain whether there exists any relationship between income inequality and net migration rate. The research is limited to linear relationship.

- For the states with statistically significant correlations, models of linear regression are developed with reference to equation 1 . The calculations are made by employing "SPSS Statistics" software.

- On the basis of the estimations and the results of the correlation and regression analyses, the impact of income inequality on population's migration in different state groups with different income inequality levels and different migration flows is assessed.

\section{The Results of the Research Concerning the Impact of Income Inequality on Population's Migration}

The research is conducted following the stages intended in the third part of the work: at first, the states under consideration are grouped by the attributes identified; then, the impact of income inequality on population's emigration and immigration is assessed.

The Groups of the EU Member States by their Income Inequality and Net Migration Rates
By their average net migration rates per 1000 persons, EU Member States are divided into two groups: one group covers the states with a positive average net migration rate per 1000 persons, while the second group encompasses the states with a negative average net migration rate per 1000 persons. Further in the research, by the values of their Gini index, the EU Member States are divided into 3 groups: the states with a low income inequality rate (Gini index is lower than 25); the states with a medium income inequality rate (Gini index varies between 25 and 35); the states with a high income inequality rate (Gini index is higher than 35). Finally, with consideration of their net migration rates per 1000 persons and Gini index values, the EU Member States are divided into 6 groups (see Figure 1).

Figure 1 indicates that the first group covers the states with a positive net migration rate per 1000 persons and a low income inequality rate, i.e. the Czech Republic, Slovenia and Slovakia. The second group, which is largest, encompasses the states with a positive net migration rate per 1000 persons and a medium income inequality rate (Gini index varies from 25 to 35), i.e. Belgium, Denmark, Germany, Ireland, Spain, France, Italy, Cyprus, Luxembourg, Hungary, Malta, the Netherlands, Austria, Finland, Sweden and the UK.

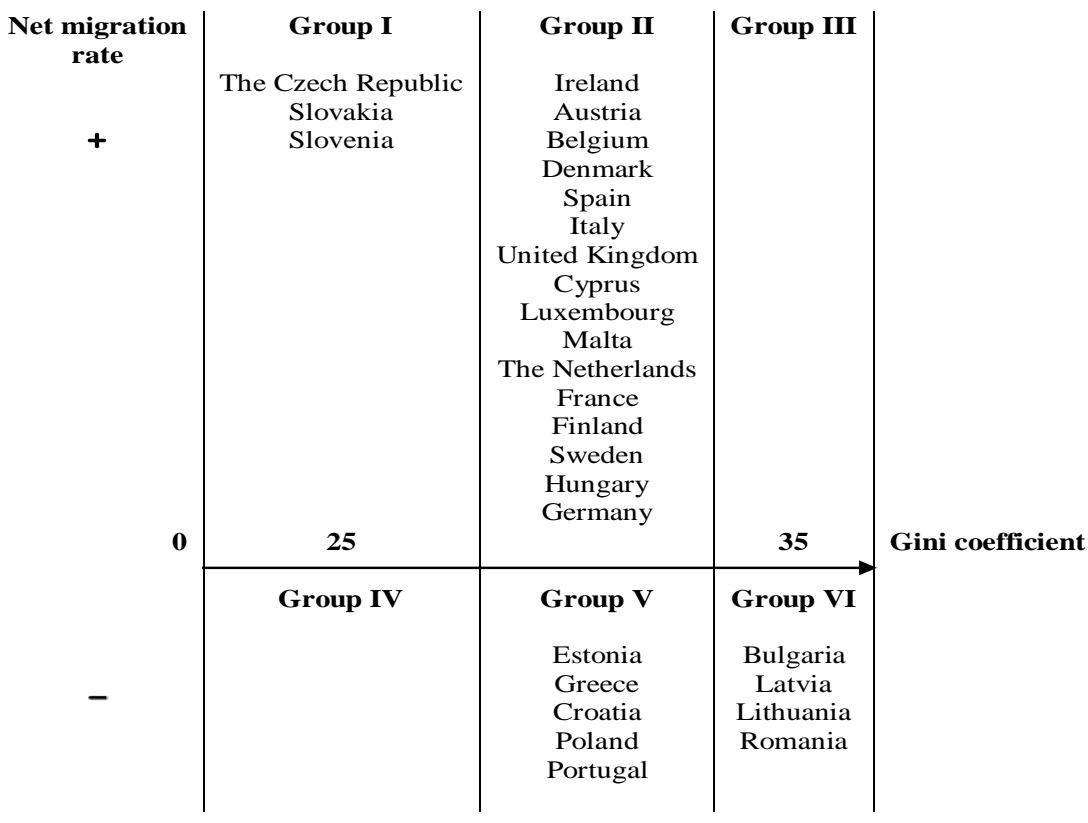

Figure 1. EU Member State groups by their net migration rates per 1000 persons and Gini index values

As it can be seen from Figure 1, the third and fourth groups do not encompass any of the states under consideration, which proposes that the EU does not comprise any states with a high income inequality rate and the number of immigrants larger than the number of emigrants, or any states with a low income inequality rate and the number of emigrants larger than the number of immigrants. The fifth group includes the states with a medium income inequality rate (Gini index varies from 25 to 35) and a negative net migration rate per 1000 persons, i.e. Estonia, Greece, Croatia, Poland and Portugal. At last, the sixth group covers the states with a negative net migration rate per 1000 persons and a high income inequality rate (Gini index is higher than 35), i.e. Bulgaria, Latvia, Lithuania and Romania.

\section{The Impact of Income Inequality on Emigration}

After state grouping, the impact of income inequality on population's emigration is assessed. Table 3 provides the results of the correlation analysis that help to assess the relationship between income inequality and emigration in different EU states and state groups. 
Daiva Laskiene, Ineta Zykiene, Paulina Verdnikovaite. Assessment of the Impact of Income Inequality on ...

Table 3

Correlation between Gini index and the Number of Emigrants in Different EU State Groups

\begin{tabular}{|c|c|c|c|c|c|c|}
\hline Group & State & p-value & Significance & $\begin{array}{c}\text { Correlation } \\
\text { coefficient, } R\end{array}$ & $\begin{array}{c}\text { Relationship } \\
\text { strength }\end{array}$ & $\begin{array}{c}\text { Relationship } \\
\text { direction }\end{array}$ \\
\hline \multirow{3}{*}{$\mathbf{I}$} & Czech Republic & 0.754 & Insignificant & 0.107 & Very weak & Direct \\
\hline & Slovakia & 0.370 & Insignificant & -0.300 & Weak & Inverse \\
\hline & Slovenia & 0.312 & Insignificant & -0.336 & Weak & Inverse \\
\hline \multirow{16}{*}{ II } & Ireland & 0.659 & Insignificant & -0.150 & Very weak & Inverse \\
\hline & Austria & 0.639 & Insignificant & 0.160 & Very weak & Direct \\
\hline & Belgium & 0.041 & Significant & -0.686 & Medium & Inverse \\
\hline & Denmark & 0.030 & Significant & 0.650 & Medium & Direct \\
\hline & Spain & 0.119 & Insignificant & 0.498 & Medium & Direct \\
\hline & Italy & 0.011 & Significant & 0.728 & Strong & Direct \\
\hline & The UK & 0.030 & Significant & 0.651 & Medium & Direct \\
\hline & Cyprus & 0.002 & Significant & 0.844 & Strong & Direct \\
\hline & Luxembourg & 0.018 & Significant & 0.693 & Medium & Direct \\
\hline & Malta & 0.057 & Insignificant & 0.588 & Medium & Direct \\
\hline & The Netherlands & 0.104 & Insignificant & -0.514 & Medium & Inverse \\
\hline & France & 0.543 & Insignificant & 0.206 & Weak & Direct \\
\hline & Finland & 0065 & Insignificant & -0.574 & Medium & Inverse \\
\hline & Sweden & 0.758 & Insignificant & 0.105 & Very weak & Direct \\
\hline & Hungary & 0.000 & Significant & 0.891 & Strong & Direct \\
\hline & Germany & 0.170 & Insignificant & 0.445 & Medium & Direct \\
\hline \multirow{5}{*}{$\mathbf{V}$} & Estonia & 0.626 & Insignificant & 0.166 & Very weak & Direct \\
\hline & Greece & 0.066 & Insignificant & 0.572 & Medium & Direct \\
\hline & Croatia & 0.007 & Significant & -0.854 & Strong & Inverse \\
\hline & Poland & 0.150 & Insignificant & -0.490 & Medium & Inverse \\
\hline & Portugal & 0.038 & Significant & -0.630 & Medium & Inverse \\
\hline \multirow{4}{*}{ VI } & Bulgaria & 0.136 & Insignificant & 0.622 & Medium & Direct \\
\hline & Latvia & 0.056 & Insignificant & 0.589 & Medium & Direct \\
\hline & Lithuania & 0.251 & Insignificant & 0.379 & Weak & Direct \\
\hline & Romania & 0.724 & Insignificant & 0.128 & Very weak & Direct \\
\hline
\end{tabular}

The data in Table 3 indicate that only a small part of the EU Member States show a statistically significant linear relationship between income inequality and emigration as significance value (p) for most states is higher than reliability value 0.05 . Only 9 out of 28 EU Member States have a statistically significant linear relationship between income inequality and emigration: Belgium, Denmark, Italy, the UK, Cyprus, Luxembourg, Hungary, Croatia and Portugal. The correlation estimated for the remaining states is not linear, so the linear correlation between Gini index and net migration rate per 1000 persons is insignificant. A statistically significant linear correlation can be observed only in the second and fifth state groups. The detailed description of the correlation in different state groups has been presented below:

- The states in the first group have low income inequality rates and positive net migration rates per 1000 persons. Gini index and the number of emigrants in these states do not show any statistically significant correlation, which leads to the conclusion that the number of emigrants in the states with low income inequality rates and positive net migration rates per 1000 persons does not depend on income inequality.

- The states in the second group with medium income inequality rates and positive net migration rates per 1000 persons make the largest share of all EU Member States.
Unlike in the first group, 7 out of 16 states in the second group have statistically significant correlation coefficients:

- Significance value $\mathrm{p}=0.041$, estimated for Belgium, is lower than the selected reliability value. The correlation coefficient equal to -0.686 indicates that there exists a medium-strong inverse relationship between the variables. Hence, income inequality growth leads to the decline in the number of emigrants. The decline in the number of emigrants under the conditions of income inequality indicates that emigration is a complex phenomenon, conditioned not only by income differences.

- The other states in the second group with statistically significant relationships show a direct link between income inequality and the number of emigrants: income inequality growth in these states leads to an increase in the number of emigrants, while the reduction in income inequality determines a smaller number of emigrants. Such relationship is inherent to Denmark, Italy, the UK, Cyprus, Luxembourg and Hungary. Hence, emigration in the states with medium income inequality rates and positive net migration rates per 1000 persons is linearly dependent on income inequality. With reference to the theoretical propositions, this tendency is common because worsening living conditions serve as an incentive to emigrate.

- Since the research has not disclosed any states with high income inequality rates and positive net migration rates 
per 1000 persons or any states with low income inequality rates and negative net migration rates per 1000 persons, the third and fourth groups fall out of the research.

- The fifth group covers the states with medium income inequality rates and negative net migration rates. The statistically significant correlation can only be observed in Croatia and Portugal. This state group demonstrates an inverse relationship meaning that the phenomena vary in different directions. Hence, the states with medium income inequality rates and negative net migration rates per 1000 persons demonstrate an inverse interdependence between emigration and income inequality.

Most significant differences are observed between the fifth and second state groups with different direction of the correlation.

- The sixth group encompasses the states with high income inequality rates and negative net migration rates per 1000 persons. Neither state in the sixth group demonstrates a statistically significant relationship between income inequality and migration, which proposes that the number of emigrants in the states with high income inequality rates and negative net migration rates per 1000 persons does not depend on income inequality. Most significant similarities are observed between the first and the sixth state groups both of them do not demonstrate any statistically significant correlation.

As previously mentioned, correlation analysis indicates whether there exists any interdependence between two phenomena. To determine causality, the method of regression analysis was employed. Linear regression analysis was performed only for the states with Gini index statistically significantly correlating with the number of emigrants. The results of the calculations are presented in Table 4 . The coefficient of determination $\mathrm{R}^{2}$ indicates which percentage of the variance in the number of emigrants can be explained by the variance in Gini index. The interdependence between the variables is best revealed by the regression equation: the regression equation coefficient at independent variable $\mathrm{x}$ (Gini index) indicates what variance in the number of emigrants is caused by a onepercentage-point increase in Gini index. A constant represents the number of emigrants that does not depend on the variance in Gini index.

Regression between Gini Index and the Number of Emigrants in Different EU Member State Groups

Table 4

\begin{tabular}{|c|c|c|c|c|}
\hline Group & State & Model significance, $p$ & Coefficient of determination, $\mathbf{R}^{2}$ & Regression equation \\
\hline \multirow{7}{*}{ II } & Belgium & 0.041 & 0.471 & $y=-27.688 x+815.394$ \\
\hline & Denmark & 0.030 & 0.423 & $y=3.902 x-60.080$ \\
\hline & Italy & 0.011 & 0.530 & $\mathrm{y}=48.590 \mathrm{x}-1.458 .938$ \\
\hline & The UK & 0.030 & 0.424 & $\mathrm{y}=22.139 \mathrm{x}-372.524$ \\
\hline & Cyprus & 0.002 & 0.712 & $y=3.738 x-103.870$ \\
\hline & Luxembourg & 0.018 & 0.480 & $y=826 x-12.823$ \\
\hline & Hungary & 0.000 & 0.794 & $y=8.176 x-194.283$ \\
\hline \multirow{2}{*}{ V } & Croatia & 0.007 & 0.729 & $y=-17.374 x+555.388$ \\
\hline & Portugal & 0.038 & 0.397 & $y=-9.660 x+368.573$ \\
\hline
\end{tabular}

The results of the regression analysis indicate that the linear regression models developed for Belgium, Denmark, Italy, the UK, Cyprus, Luxembourg, Hungary, Croatia and Portugal are statistically significant as $p<0.05$. The model equations reveal how the number of emigrants in each of the states varies depending on the variance in Gini index. The above-mentioned states also demonstrate a statistically significant linear relationship between the variables. The coefficient of determination, which reveals if a model is reliable, varies in the interval from 0.397 to 0.794 . This means that $39.7-79.4 \%$ of the variance in the number of emigrants in the states under consideration can be explained by the variance in Gini index. The most accurate regression model shows the interdependence between the number of emigrants and income inequality in Hungary, while the least accurate model describes the interdependence between the variables in Portugal. Nevertheless, it can still be stated that the results of this research for most states under consideration correspond to the theoretical presumptions - high income inequality rates lead to higher emigration rates. It is also the case that the impact of income inequality on emigration is similar in the states within a group, but differs between the groups. Income inequality promotes population's emigration in nearly all states attributed to the second group, with the exception of Belgium, where income inequality rowth reduces population's emigration rates. It proposes that the impact of one variable on the other may differ even in relatively similar states. In both states attributed to the fifth group, the impact of income inequality on emigration is the same: the growth in Gini index leads to the decline in the number of emigrants. It can be concluded that income inequality affects emigration only in the states with medium income inequality rates (Gini index varies from 25 to 35). The direct interdependence between the variables is inherent to the states with positive net migration rates per 1000 persons, while the inverse relationship between the variables is inherent to the states with negative net migration rates per 1000 persons.

\section{The Impact of Income Inequality on Immigration}

The results of the correlation analysis, which helped to assess the relationship between income inequality and immigration in different EU Member State groups, are presented in Table 5. 
Correlation between Gini index and the Number of Immigrants in Different EU Member State Groups

\begin{tabular}{|c|c|c|c|c|c|c|}
\hline Group & State & p-value & Significance & Correlation coefficient & Relationship strength & Relationship direction \\
\hline \multirow{3}{*}{$\mathbf{I}$} & Czech Republic & 0.761 & Insignificant & 0.104 & Very weak & Direct \\
\hline & Slovakia & 0.022 & Significant & -0.678 & Medium & Inverse \\
\hline & Slovenia & 0.004 & Significant & -0.787 & Strong & Inverse \\
\hline \multirow{16}{*}{ II } & Ireland & 0.212 & Insignificant & 0.409 & Medium & Direct \\
\hline & Austria & 0.766 & Insignificant & -0.102 & Very weak & Inverse \\
\hline & Belgium & 0.233 & Insignificant & 0.443 & Medium & Direct \\
\hline & Denmark & 0.170 & Insignificant & 0.445 & Medium & Direct \\
\hline & Spain & 0.007 & Significant & -0.758 & Strong & Inverse \\
\hline & Italy & 0.002 & Significant & -0.822 & Strong & Inverse \\
\hline & The UK & 0.206 & Insignificant & 0.414 & Medium & Direct \\
\hline & Cyprus & 0.000 & Significant & -0.922 & Very strong & Inverse \\
\hline & Luxembourg & 0.077 & Insignificant & 0.553 & Medium & Direct \\
\hline & Malta & 0.143 & Insignificant & 0.472 & Medium & Direct \\
\hline & The Netherlands & 0.358 & Insignificant & 0.307 & Weak & Direct \\
\hline & France & 0.776 & Insignificant & 0.097 & Very weak & Direct \\
\hline & Finland & 0.251 & Insignificant & -0.378 & Weak & Inverse \\
\hline & Sweden & 0.006 & Significant & 0.769 & Strong & Direct \\
\hline & Hungary & 0.007 & Significant & 0.758 & Strong & Direct \\
\hline & Germany & 0.206 & Insignificant & 0.413 & Medium & Direct \\
\hline \multirow{5}{*}{$\mathbf{V}$} & Estonia & 0.647 & Insignificant & 0.156 & Very weak & Direct \\
\hline & Greece & 0.987 & Insignificant & 0.005 & Very weak & Direct \\
\hline & Croatia & 0.004 & Significant & -0.876 & Strong & Inverse \\
\hline & Poland & 0.008 & Significant & -0.748 & Strong & Inverse \\
\hline & Portugal & 0.771 & Insignificant & 0.100 & Very weak & Direct \\
\hline \multirow{4}{*}{ VI } & Bulgaria & 0.250 & Insignificant & 0.503 & Medium & Direct \\
\hline & Latvia & 0.034 & Significant & -0.639 & Medium & Inverse \\
\hline & Lithuania & 0.885 & Insignificant & 0.050 & Very weak & Direct \\
\hline & Romania & 0.031 & Significant & -0.680 & Medium & Inverse \\
\hline
\end{tabular}

The data in Table 5 show that income inequality statistically significantly correlates with immigration in almost one-third of EU Member States: 11 out of $28 \mathrm{EU}$ Member States demonstrate the statistically significant correlation between the variables, i.e. significance value $\mathrm{p}$, estimated for 11 states, is lower than reliability value 0.05 . Unlike in the case of emigration, the number of immigrants correlates with Gini index in all state groups under consideration. In the first state group, the statistically significant correlation between the variables was estimated for Slovakia and Slovenia; in the second state group - for Spain, Italy, Cyprus, Sweden and Hungary; in the fifth state group - for Croatia and Poland; in the sixth state group - for Latvia and Romania. The results propose that the relationship between Gini index and immigration exists irrespective of income inequality and net migration rates in a state.

The detailed description of the correlation in different state groups has been presented below:

- The states in the first group have low income inequality rates and positive net migration rates per 1000 persons. The correlation between the variables is statistically significant in Slovakia and Slovenia. Hence, the states in the first group tend to have an inverse relationship between the variables, which proposes that the growth in Gini index leads to the decline in the number of immigrants.

- The states in the second group are characterised by medium income inequality rates and positive net migration rates per 1000 persons; this group covers the largest number of the states where income inequality statistically significantly correlates with immigration. The statistically significant correlation that indicates an inverse relationship between the variables is inherent to Spain, Italy and Cyprus. In the states with an inverse correlation, growing income inequality rates lead to the decline in immigration. The opposite trends are observed in Sweden and Hungary where the relationship between the variables is direct, i.e. growing Gini index in Sweden and Hungary leads to an increase in the number of immigrants. Although the states in the second group are similar in terms of their income inequality and migration, the relationship between the variables estimated for the states in this group is different.

- Since the research has not disclosed any states attributable to the third and fourth groups, they fall out of the research.

- The fifth group encompasses the states with medium income inequality and negative net migration rates. In this group, the statistically significant correlation between the variables is inherent to Croatia and Poland. The negative correlation estimated for both states indicates an inverse relationship between the variables, i.e. the growth in income inequality leads to the decline in the number of immigrants.

- The sixth group covers the states with high income inequality and negative net migration rates. Latvia and Romania demonstrate a statistically significant correlation between income inequality and immigration. The relationship between the variables is inverse.

When assessing the results of the correlation analysis for different state groups, some similarities can be observed. The states in the first, fifth and sixth groups as well as a part of the states in the second group demonstrate an inverse relationship between income inequality and immigration, i.e. increasing household income gaps reduce the attractiveness of the states to immigrants. Nevertheless, it cannot be stated 
that it is inherent to all the states because, for instance, a direct relationship between the variables in Sweden and Hungary indicates that even with growing income inequality rates, the states can attract more immigrants.

To research the interdependence between immigration and income inequality, the method of regression analysis was employed. Linear regression analysis was performed for the states with Gini index statistically significantly correlating with the number of immigrants (see Table 5). The models of regression analysis developed for each of the states are presented in Table 6. The value of the coefficient of determination, denoted $\mathrm{R}^{2}$, indicates which percentage of the variation in the number of immigrants can be explained by the variation in Gini index. The regression equation coefficient at independent variable $\mathrm{x}$ (Gini index) indicates what variance in the number of immigrants is caused by a one-percentage-point increase in Gini index. A constant represents the number of immigrants that does not depend on the variance in Gini index.

Regression between Gini Index and the Number of Immigrants in EU Member State Groups

Table 6

\begin{tabular}{|c|c|c|c|c|}
\hline Group & State & Model significance, $\mathbf{p}$ & Coefficient of determination, $\mathbf{R}^{\mathbf{2}}$ & Regression equation \\
\hline \multirow{3}{*}{ I } & Slovakia & 0.022 & 0.460 & $\mathrm{y}=-995 \mathrm{x}+31.083$ \\
\cline { 2 - 5 } & Slovenia & 0.004 & 0.619 & $\mathrm{y}=-8.362 \mathrm{x}+219.013$ \\
\hline \multirow{4}{*}{ II } & Spain & 0.007 & 0.574 & $\mathrm{y}=-161.325 \mathrm{x}+5.875 .709$ \\
\cline { 2 - 5 } & Italy & 0.002 & 0.676 & $\mathrm{y}=-141.811 \mathrm{x}+4.959 .327$ \\
\cline { 2 - 5 } & Cyprus & 0.000 & 0.851 & $\mathrm{y}=-2.075 \mathrm{x}+82.757$ \\
\cline { 2 - 5 } & Sweden & 0.006 & 0.591 & $\mathrm{y}=13.764 \mathrm{x}-242.868$ \\
\cline { 2 - 5 } & Hungary & 0.007 & 0.575 & $\mathrm{y}=-7.008 \mathrm{x}-147.052$ \\
\hline \multirow{2}{*}{ V } & Croatia & 0.004 & 0.768 & $\mathrm{y}=-67.857 \mathrm{x}+117.907$ \\
\cline { 2 - 5 } & Poland & 0.008 & 0.560 & $\mathrm{y}=-1.895 \mathrm{x}+75.765$ \\
\hline \multirow{2}{*}{ VI } & Latvia & 0.034 & 0.408 & $\mathrm{y}=-7.896 \mathrm{x}+421.090$ \\
\cline { 2 - 5 } & Romania & 0.031 & 0.462 & \\
\hline
\end{tabular}

The results of the regression analysis indicate that the models of linear regression developed for Slovakia, Slovenia, Spain, Italy, Sweden, Cyprus, Poland, Hungary, Croatia, Latvia and Romania are statistically significant as $\mathrm{p}<0.05$. The regression equations reveal that the variance in Gini index determines the variance in the number of immigrants in each of the states. The coefficient of determination, which reflects reliability of the models, varies in the interval from 0.408 to 0.851 . It means that $40.8-85.1 \%$ of the variance in the number of immigrants in the above-mentioned states can be explained by the variance in Gini index. The larger interval of the coefficients of determination shows that the models more accurately describe the impact of income inequality on immigration than on emigration. The most accurate regression model shows the interdependence between the number of immigrants and income inequality in Cyprus, while the least accurate model describes the interdependence between the variables in Latvia. Nevertheless, it can still be stated that the results of this research for most states under consideration correspond to the theoretical presumptions - high income inequality rates lead to less intensive flows of immigrants. This tendency can be observed in the first, fifth and sixth state groups and a part of states in the second group. Some differences can be seen within the second group. For instance, growing income inequality in Sweden and Hungary leads to an increase in the number of immigrants. It proposes that the impact of one variable on the other may differ even in relatively similar states. In the remaining states attributed to the second group and the other groups, population's immigration is decreasing when Gini index, reflecting income inequality, is rising. It should be noted that such states as Italy, Cyprus, Hungary and Croatia demonstrate linear relationships between both sets of variables - Gini index and immigration, and Gini index and emigration.

To conclude, income inequality in different EU Member State groups has a more significant impact on population's immigration than on emigration. The results of this research correspond to the theoretical presumptions - in most states under consideration, high income inequality rates reduce attractiveness of a state and lead to the decline in the number of immigrants.

\section{Conclusions}

Scientific studies and statistical data propose that income inequality can significantly affect population's migration. For this reason, the relationship between the above-mentioned phenomena calls for deeper research. Income inequality is recognized as one of the main causes of emigration. This research has revealed that the impact of income inequality on population's migration in the EU Member States may vary and linearly manifests only in a small part of the states. In the states attributed to the first group (with low income inequality and positive net migration rates), growing income inequality does not have any direct impact on emigration, but leads to the decline in immigration. This could be due to the fact that countries such as the Czech Republic, Slovenia and Slovakia have a very high but fairly evenly distributed average income per capita compared to other developed countries in the EU. Therefore, it could be assumed that a sense of equality does not encourage people to emigrate, and the possibility to earn only a relatively modest income in these countries does not encourage immigration processes. The effects of income inequality on population's migration in the states attributed to the second group (with medium income inequality and positive net migration rates) may differ. For instance, growing income inequality determines a decline in the number of emigrants in Belgium, but leads to an increase in the number of emigrants in the remaining states of this group. In Spain, Italy and Cyprus, income inequality growth determines a decline in the number of immigrants, while in Sweden and Hungary it causes the number of immigrants to rise. The results of this group of 
countries show that as income inequality increases, so does emigration from these countries, although most of the countries in this group are economically strong. It is thought that this could be influenced by a number of factors that should be analyzed in more detailed further studies. By employing state grouping method, it has been found that the EU does not comprise any states with high income inequality rates and the number of immigrants larger than the number of emigrants, or any states with low income inequality rates and the number of emigrants larger than the number of immigrants. In the states attributed to the fifth group (with medium income inequality and negative net migration rates), rising income inequality leads to a decline in the number of both emigrants and immigrants. Consequently, the average level of income inequality leads to a decrease in migration processes in countries with a relatively average level of income compared to other EU countries (Estonia, Greece, Portugal, Poland, Croatia). A more detailed analysis of the factors determining such processes would provide interesting insights. In the states attributed to the sixth group (with high income inequality and negative net migration rates), income inequality does not have any direct impact on emigration, but determines declining immigration. It should be mentioned that the countries in this group have not only a high level of income inequality, but also a relatively low average income, so it is not surprising that this does not encourage immigration to these countries. Hence, income inequality has a more significant impact on population's immigration than on emigration in all EU Member State groups. Income inequality causes population's emigration only in the states with medium income inequality rates.

Results of the paper lead to perspective of further research which would include deeper analysis of causes that lead to income inequality and migration processes. To authors opinion qualitative methods would be helpful to investigate the reasons of immigration and emigration and their connection with income inequality in both micro and macro level. The results of further research could be useful as recommendations for social and economic policy implications.

\section{References}

Arslan, A., \& Taylor, J. E. (2012). Transforming rural economies: migration, income generation and inequality in rural Mexico. Journal of Development Studies, 48(8), 1156-1176. https://doi.org/10.1080/00220388.2012.682985

Barciukiene, D. (2007). Skurdas Lietuvos kaime: paplitimas, priezastys ir mazinimo budai. Socialine teorija, empirija, politika ir praktika, 4, 132-143. https://doi.org/10.15388/STEPP.2007.4.8713

Barham, B., \& Boucher, S. (1998). Migration, remittances, and inequality: estimating the net effects of migration on income distribution. Journal of development economics, 55(2), 307-331. https://doi.org/10.1016/S03043878(98)90038-4

Bekesiene, S. (2015). Duomenu analizes SPSS pagrindai: mokomoji knyga. Vilnius: Generolo Jono Zemaicio Lietuvos karo akademija.

Brzezinski, M. (2013). Income polarization and economic growth. National Bank of Poland working paper, (147). https://doi.org/10.2139/ssrn.2244858

Burzynski, M., Deuster, C., Docquier, F., \& de Melo, J. (2019). Climate Change, Inequality, and Human Migration. CEPR Discussion Paper No. DP13997. Available at: https://ssrn.com/abstract=3464525

Card, D. (2009). Immigration and inequality. American Economic Review, 99(2), 1-21. http://dx.doi.org/10.1257 /aer.99.2.1

Collins, F. L. (2020). Legislated inequality: Provisional migration and the stratification of migrant lives. In Intersections of inequality, migration and diversification (pp. 65-86). Palgrave Pivot, Cham. https://doi.org/10.1007/978-3-03019099-6_4

Dauderstadt, M. (2017). Reducing European Inequality: Cohesion Through Convergence. Social Europe. Available from internet: https://www.socialeurope.eu/reducing-european-inequality-cohesion-convergence

Dodani, S., \& LaPorte, E. R. (2005). Brain drain from developing countries: how can brain drain be converted into wisdom gain? Journal of The Royal Society of Medicine, 98(11), 487-491. http://dx.doi.org/10.1258/jrsm.98.11.487

Eurostat (2018). Distribution of income database. Available from internet: https://ec.europa.eu/eurostat/data/database

Ganic, M. (2019). The Labour Market, Social Inequality and the Role of Emigration: The Case of the Western Balkan Economies. In Western Balkan Economies in Transition (pp. 61-72). Springer, Cham. https://doi.org/10.1007/978-3319-93665-9_5

Giziene, V., \& Markauskiene, A. (2012). Investiciju ị aukstaji issilavinima ir valstybes pajamu bei islaidu priklausomybes tyrimas. Economics and management, 17(3), 1141-1148. http://dx.doi.org/10.5755/j01.em.17.3.2135

Guvenen, F., Kuruscu, B., \& Ozkan, S. (2014). Taxation of human capital and wage inequality: A cross-country analysis. Review of Economic Studies, 81(2), 818-850. https://doi.org/10.1093/restud/rdt042

Halter, D., Oechslin, M., \& Zweimuller, J. (2014). Inequality and growth: the neglected time dimension. Journal of economic growth, 19(1), 81-104. https://doi.org/10.1007/s10887-013-9099-8

Howell, A. (2017). Impacts of migration and remittances on ethnic income inequality in rural China. World Development, 94, 200-211. https://doi.org/10.1016/j.worlddev.2017.01.005 
Jovanovic, M. (2002). European economic integration: limits and prospects. Routledge. https://doi.org/10. 4324/9780203009864

Kaminskiene, R. (2009). Demografiniai statistiniai rodikliai ir migracijos srautai. Vilnius: Iseivijos institutas.

Kasiulevicius, V., \& Denapiene, G. (2008). Statistikos taikymas moksliniu tyrimu analizeje. Gerontologija, 9(3), 176-180. Available from internet: http://www.gerontologija.lt/files/edit_files/File/pdf/2008/nr_3/2008_176_180.pdf

Koczan, Z., \& Loyola, F. (2018). How do migration and remittances affect inequality? A case study of Mexico. International Monetary Fund. https://doi.org/10.5089/9781484361634.001

Kumpikaite, V., \& Zickute, I. (2012). Emigracijai ịtaka daranciu veiksniu analize. Economics and management, 17(2), 740-746. https://doi.org/10.5755/j01.em.17.2.2207

Kusunose, Y., \& Rignall, K. (2018). The long-term development impacts of international migration remittances for sending households: evidence from Morocco. Migration and Development, 7(3), 412-434. https://doi.org/10. 1080/21632324.2018.1475383

Lazutka, R. (2017). Pajamu nelygybe - gresme demokratijai. Available from internet: http://www.pramprof.lt /index.php/news/222-r-lazutka-pajamu-nelygybe-gresme-demokratijai

Lynch, E. (2017). Trade Unions On Frontline In Battle Against Inequality. Available from internet: https://www.socialeurope.eu/trade-unions-frontline-battle-inequality

Martinaitis, Z., \& Zvalionyte, D. (2007). Emigracija is Lietuvos: ka zinome, ko nezinome ir ka turetume zinoti. Politologija, 3(47), 112-134.

Massey, D. S., Vila-Belda, J. A., Hugo, G., Kouaouci, A., \& Pellegrino, A. (2006). Theories of international migration: A review and appraisal. In The migration reader: Exploring politics and policies (pp. 34-62). Lynne Rienner Publishers.

Matuzeviciute, K., \& Balciunas, S. (2012). Emigrantu elgsena, susijusi su piniginiais pervedimais ir ju panaudojimu: Lietuvos atvejis. Ekonomika ir vadyba: aktualijos ir perspektyvos, 4(28), 142-151.

Mishchuk, H., Samoliuk, N., Bilan, Y., \& Streimikiene, D. (2018). Income inequality and its consequences within the framework of social justice. Problemy Ekorozwoju, 13(2).

Obstfeld, M., \& Krugman, P. R. (2003). International Economics: Theory and Policy. Pearson Education, Inc.

Orrenius, P. M., \& Zavodny, M. (2018). Does Migration Cause Income Inequality? (2018). Mission Foods Texas-Mexico Center Research. Available at: https://scholar.smu.edu/texasmexico-research/1

Porumbescu, A. (2015). Defining the new economics of labor migration theory boundaries: a sociological-level analysis of international migration. Revista de Stiinte Politice. Revue des Sciences Politiques, (45), 55-64.

Pukeliene, V., Glinskiene, R., \& Berzinskiene, D. (2007). Darbo jegos migracija: globalinis aspektas. Taikomoji ekonomika: sisteminiai tyrimai, 2, 49-64.

Pukenas, K. (2005). Sportiniu tyrimu duomenu analize SPSS programa:mokomoji knyga. Kaunas: LKKA.

Schiff, M. (2018). Beneficial Brain Drain and Non-Migrants' Welfare. Institute of Labor Economics (IZA), 11483. Available from internet: https://papers.ssrn.com/sol3/papers.cfm?abstract_id=3170272

Skuciene, D. (2008). Pajamu nelygybe Lietuvoje. Filosofija. Sociologija, 19 (4), 22-33.

Skuciene, D., \& Gabnyte, V. (2018). Skurdas kaimo vietovese Lietuvoje. Lietuvos socialine raida: socialines ịtraukties politikos Lietuvoje igyvendinimas, 48-64.

Slettebak, M. H. (2020). Labour migration and increasing inequality in Norway. Acta Sociologica, https://doi.org/10.1177/0001699320930261.

Stark, O. (2005). Inequality and migration: A behavioral link. Economics Letters, 91(1), 146-152. https://doi.org/10. 1016/j.econlet.2005.09.015

Tonkunaite-Thiemann, A. (2012). Migrantai kaip „gerai informuoti pilieciai“: gimtosios salies visuomeneje vykstanciu socialiniu reiskiniu vertinimas. Socialine teorija, empirija, politika ir praktika, 6, 97-111. https://doi.org/10. 15388/STEPP.2012.0.1855

Tsoukalis, L. (1993). The new European economy: the politics and economics of integration. Oxford University Press, USA.

Uprety, D. (2019). Does Skilled Migration Cause Income Inequality in the Source Country? International Migration. https://doi.org/10.1111/imig.12661

The article has been reviewed.

Received in January 2020; accepted in December 2020.

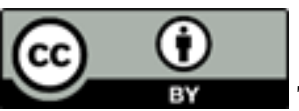

This article is an Open Access article distributed under the terms and conditions of the Creative Commons Attribution 4.0 (CC BY 4.0) License (http://creativecommons.org/licenses/by/4.0/). 